\title{
Calprotectin Complex Interactions with Phytoquinolines and New Target Binding Alternates Calprotectin complex and Phytoquinolines
}

\author{
Muthukrishnan Suriyavathana* and Meleveetil Vidhya \\ Department of Biochemistry, Periyar University, Salem-11, Tamil Nadu. INDIA.
}

\begin{abstract}
Objective: S100 proteins, the low molecular weight calcium binding proteins, have 'EF hand' type conformation. They are identified as markers for various diseases. A member of S100 protein family, S100A9 is involved, in performing important biological functions, by coordinating with S100A8. S100A9 targeted interactions of quinoline-3carboxamides, differentiates quinoline derivative interaction among varying single point substituents. Inhibition of protein interaction with many important biological markers as RAGE, TLR4/MD2 and others, was accomplished by quinoline-3-carboxamides. Methods: Two quinoline derivatives identified from Toddalia aculeata are analysed for their molecular and ligand properties. Results: Toxicity analysis, show ADMET properties of phytoquinolines, to be supportive. Molecular binding with S100A9 and its heteromer formed with S100A8, are found analogous to binding, with substituted quinoline-3carboxamides. Among the various ligands used, a phytoquinoline derivative, and methyl substituted quinoline-3-carboxamide, show most stable interactions. Conclusion: This study proposes the use of compounds from source, as potential ligands to target marker S100A9 and its heterodimer.
\end{abstract}

Key words: Quinoline, Calprotectin, Molecular Interaction, Ligand, ADMET.

\section{INTRODUCTION}

The calcium binding S100 proteins with an $\mathrm{EF}$ hand like domain, are targeted in drug discovery and development for many diseases, including tumours, epidermal differentiation, anatomic pathology and also for inflammatory diseases. ${ }^{1}$ The Migration Inhibitory Factor related protein (MRP-14 or S100A9), functions in coordination with MRP-8 or S100A8, in regulating the myeloid cell function by binding to Toll like receptor- $4{ }^{2}$ These promote cardiomyocyte dysfunction through receptors for advanced glycation end products, ${ }^{3}$ or bind small molecules as quinoline-3-carboxamides. ${ }^{4}$ The protein and its heterodimer with S100A8, are focused on, in analysing autoimmune diseases. ${ }^{4}$

Binding of bivalent metal ions of calcium and zinc to proteins, have significant influence on the conformation and oligomeric state, of the quaternary complexes. Functional diversity is attained through various chemical and conformational specifications, structural plasticity at the quaternary level, of each monomer present in the complex. Metal binding also influence non-bonded interactions, which enhance function and diversification in protein complexes. The properties of individual protein, including chemical and conformational properties, structural plasticity at quaternary level, interactions with metal ions, oligomeric and fibrillar amyloid formation through noncovalent assembly, enable functional diversity among these proteins. ${ }^{5}$

Both the members of S100, S100A8 (MRP8) and S100A9 (MPP14) independently form homodimers, apart from the formation of heterodimer or heterotetramer. ${ }^{6,7}$
Submission Date: 27-01-2017; Revision Date: 15-03-2017; Accepted Date: 30-03-2017

DOI: $10.5530 / \mathrm{ijper.51.4.97}$ Correspondence: Dr. Muthukrishnan Suriyavathana,

Asst. Professor,

Department of Biochemistry, Periyar Palkalai Nagar, Salem, Tamil Nadu - 636011, INDIA.

Tel.no: 9894329286

E-mail: suriyaveda@yahoo. co.in

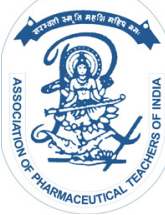

www.ijper.org 
Characterization of proteins, in the presence and absence of bivalent cations, reveals the significance of $\mathrm{Ca}^{2+}$ in heterodimer of S100A8 and S100A9 during tetra merization. ${ }^{8}$ Tetramerization occurs upon $\mathrm{Ca} 2+$ binding and the final complex is found to bind to $8 \mathrm{Ca} 2+.{ }^{5}$

S100 members involve in intracellular and extracellular regulatory activities. Their interactions provide, important enzyme regulatory functions, dynamics of cytoskeletal constituents, growth and differentiation of cell, and homeostasis of bivalent calcium ions. Their extracellular activities include secretion, regulation of inflammatory cells, neurons, astrocytes, cell surface receptor RAGE and others. ${ }^{9}$

Cross-bridges are formed between homologous or heterologous target proteins, by exposure of two binding surfaces on opposite sides. Targets are shared by different members of S100, but binding is highly specific which indicate their role in specific activities, although there are multiple targets or common targets for these members. ${ }^{10}$

S100 protein family consists of 16 member proteins. These members form homodimer, heterodimer, heterotetramer or polymers. The target proteins taken from this family, form ligand to important biological targets as RAGE or TNF- $\alpha$. S100A9 proteins (calprotectin), are all alpha -proteins and contain an EF hand like fold. They possess calcyclin domain. It binds to calcium and zinc, and targets many biological processes, as innate immune system response, inflammatory response, metal ion binding with $\mathrm{Ca} 2+$ or $\mathrm{Zn} 2+$, other biological receptor binding as RAGE receptor binding. ${ }^{11-13}$

The expression of members, the heterodimers of S100 (calgranulins) formed with S100A8 and S100A9 and S100A12, are constitutive in neutrophils and induced in several cell types. The function of calprotectin constituting monomers of S100A8 and S100A9, may depend on cell type, mediators which are specific to inflammation, the receptors involved in recognition and post-translational modifications. These two members of S100 are under the control of pro-inflammatory and anti-inflammatory mediators. ${ }^{14}$

Quinoline derivatives are identified for their anti-microbial, anti-cancer,anti-malarial, anti-viral and anti-inflammatory activities. Different derivatives are compared, analysed and these molecules are found to successfully exhibit pharmacological properties. ${ }^{15-21}$ Carboxamide derivatives of quinoline control autoimmune disease, by targeting the S100 members, the calprotectin, especially through its binding to S100A9. A defined structureactivity relationship (SAR) emerged during the analysis of these interactions, and inhibitory interactions of RAGE, TLR4/MD2, TNF- $\alpha$. Based on these interactions, the immunomodulatory effects of quinoline-3-carboxamide derivative, were identified. Binding, in the presence of $\mathrm{Ca} 2+$ or $\mathrm{Zn} 2+$ has promoted interaction of the target to quinoline compounds, but in their absence, the binding remains at the baseline values. ${ }^{22}$

Toddalia aculeata (Lopez root), is a climbing shrub distributed in Africa, Asia and Madagascar. Their phytocompounds are widely used as an Ayurvedic medicine for a number of diseases, including rheumatism and malaria. ${ }^{23}$ The plant material taken from the branches, are processed, compounds extracted based on varying solvent polarity. Analysis of extracts done quantitatively and qualitatively reveal, alkaloids are predominantly present among various phytochemical constituents. Two derivatives of quinolines are identified from among these compounds. ${ }^{24}$ Quinoline derivatives obtained, are analysed for their molecular and biological characteristics. ${ }^{25}$ Molecular properties identified based on molecular weight, topological parameter including the number of rotatable bonds, indicate binding flexibility, information on drug-likeness of molecules based on Lipinski's 'Rule of 5' violation. Bioactivity scores for molecules, reveal the effectiveness, to perform biological function, including inhibitory properties, of molecules. Atomic coordinates of compounds are used for molecular modelling based on the atomic positions as determined by the NMR analysis, along with information obtained from chemspider database. $^{26-28}$

Molecular structures of targets are obtained from structural database. ${ }^{29}$ Comparative analysis, with structures of various substitutes of quinoline-3-carboxamides, is undertaken, to determine interaction with $\mathrm{S} 100$ member proteins. These carboxamide derivatives exhibited optimal binding, with the S100 member targets. The metabolites from $T$. aculeata are analysed for their drug-conform properties, in comparison to quinoline-3-carboxamide derivatives at R5 position (Qsub), together with the level of risk of mutagenicity, drug scores indicative of favourable drug like properties. Comparative analysis identifies phytoquinoline constituents, to possess similar characteristics and binding, with reference to specific substituent of quinolinecarboxamide derivative.

The nitrogen containing derivatives with heterocyclic ring are identified to be 16 and 17 carbon derivatives of quinolines. ${ }^{24}$ These compounds present in the source, identified through NMR structure determination, are used for virtual screening and comparative analysis with quinoline-3-carboxamide derivatives. ${ }^{25}$ 


\section{MATERIALS AND METHODS}

Phytochemical compounds from T. aculeata identified, included alkaloid derivatives. The compounds identified are N-methyl-4-hydroxy-7-methoxy-3-(2,3-epoxy3 -methylbutyl)-1H-quinolin-2-onewhich is taken as Metabolite1 and 3-(2,3-Dihydroxy-3-methylbutyl)-4,7dimethoxy-1-methyl-1H-quinolin-2-one, taken as Metabolite2. These compounds are used for comparative analysis. Figure 1

With reference to atomic coordinates obtained from NMR studies, structure of ligands fromToddalia species are modelled, ${ }^{22,23}$ based on chirality and, energy minimized structures are prepared. Molecular and Biomolecular properties, are analysed for quinoline carboxamide derivatives varying at R5 position (Qsub) and quinoline derivatives from T. aculeata. Table 1 Comparative analysis of phytoconstituents with quinoline-3-carboxamide derivatives are done, for identification of phytoconstituent suitability, as potential ligands with respect to quinoline-3-carboxamide derivatives.

The suitability of compounds is determined, based on drug-score from a statistical comparison between cLogP, $\operatorname{logS}$, Molecular Wt., Druglikeness, Risk Level of Mutagenicity, Risk level of the Tumorigenicity, Risk level of

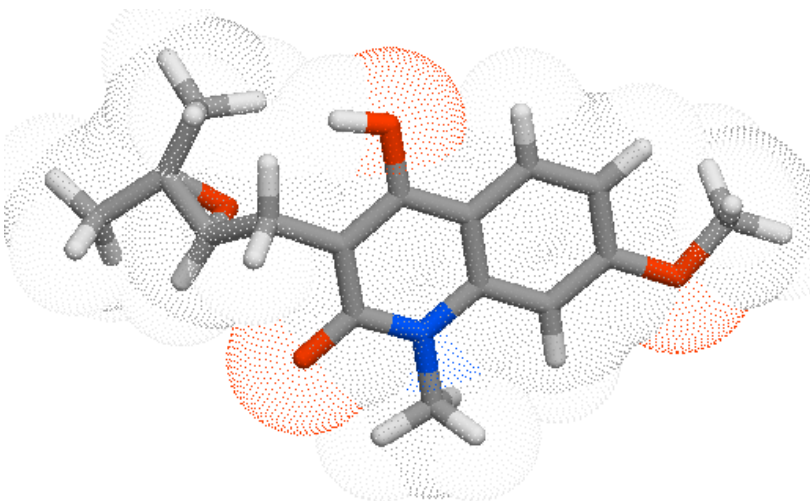

Figure 1(a): Quinoline derivative : compound1 obtained from $T$. aculeata.

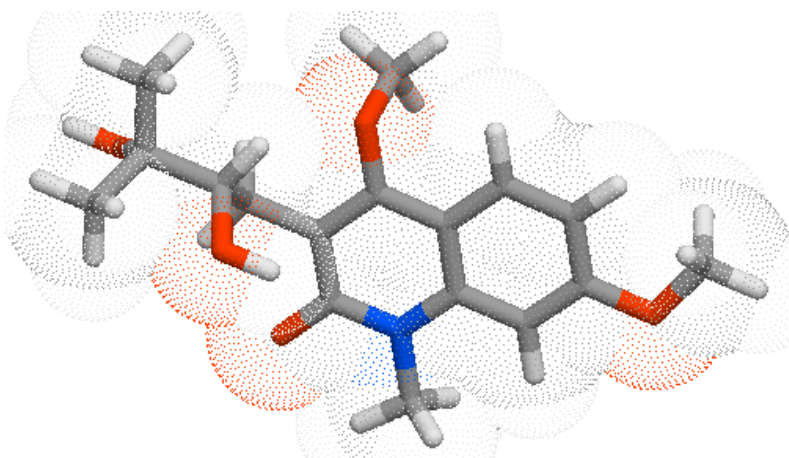

Figure 1(b): Quinoline derivative: compound2 obtained from T. aculeata reproductive levels. Table 1 Characteristic properties as hydrophilicity which reflects pharmacological properties of compounds as bioavailability is determined. ${ }^{30,31}$ Complex dataset consisting of S100 protein members, including homodimer and heterodimer is prepared, with quinoline-3-carboxamide derivatives and phytocompounds from T. aculeata, as ligands. Different derivatives taken included quinoline-3-carboxamides with substitution at $\mathrm{R} 5$ position of the compound as $\mathrm{H}$, $\mathrm{CH} 3, \mathrm{CF} 3, \mathrm{Br}, \mathrm{SCH} 3, \mathrm{CH} 2 \mathrm{CH} 3 .^{22,26}$ Interactions during complex formation are analysed, with S100A8 (MRP8) and S100A9 (MRP9) polymer members of the family. S100A9 is taken as a homodimer (1IRJ), and heterodimer calprotectin (S100A8 and S100A9)is taken (1XK4, 4GGF) from PDB. ${ }^{27}$ The structures of ligands, are geometrically optimized and docked with receptor members of S100A9.Docking is carried out based on shape and electrostatics without restraining rotational conformation. The interface residues are identified with reference to $z$ axis. The range angle parameter, is kept at 180 degrees with respect to the $z$ axis, for enabling maximum flexibility of interaction between protein and ligands, through interface residues and to obtainmost optimized structures. The best among 100 conformations, ${ }^{32}$ are used for analysis.

Intermolecular interactions as non-bonded interactions are determined. ${ }^{33}$ Small molecular interactions of homodimer complex protein (S100A9) and heterocomplex (S100A9 and S100A8) with R5 substituents of quinoline-3-carboxamides, and quinoline derivatives obtained from T. aculeata, are compared.

\section{RESULTS AND DISCUSSION}

Polymers of S100A9 and its heterocomplex with S100A8 contained Ca2+ ions bound to the protein. These metal ions enhanced the binding of protein to other molecules, and their targets. S100A9 or MRP14 dimer is found to be longer, among the two members with 113 residues while the S100A8 or MRP8 is found to be of 93 residues long.

Quinoline-3-carboxamide derivatives exhibit successful inhibitory effect, on targets belonging to S100 protein family. Various substituents at R5 position of quinolinecarboxamide compounds, are differentiated based on, their binding parameters. Homocomplexes provide better interactions, in comparison of binding among homo and heterocomplexes of S100A9 member, with quinolinecarboxamide derivatives. They exhibit, enhanced binding in the presence of metal ions.

The plant derivatives possess, $\operatorname{low} \log \mathrm{P}$ values in comparison to quinoline-3-carboxamide derivatives. 
$\log \mathrm{P}$ values less than 5 , indicate easy permeability of compounds through biological membranes which helps in increased bioavailability for the compounds. Being well within the range of required range of oral bioavailability, they also possess minimum molecular weight in comparison to all the molecules taken. The phytoderivatives, obey Lipinski's rules, and contain the required number of flexible rotatable bonds, to be considered for screening as a potential drug. Table 1 In complex interactions, only few complexes display stable interactions, upon docking. The total energy of complexes, indicated interaction stability among complexes. S100A9 complexes with small molecules, reveal maximum stability in interaction in complex with methyl substituent at R5 position of quinoline-3- carboxamide. Among the metabolites from Toddalia sp., quinoline derivative, forming metabolite1 exhibit stable interaction which is comparable to that of methyl substituent of quinolinecarboxamide derivative. The van der Waal interaction for both plant metabolites are found stable, but the electrostatic interaction of metabolite1, contributes to stability in interaction.Table 2, Figure 2

Among the heterocomplex interactions, for 1XK4 receptor protein structure, carboxamide derivatives are found to be better ligands and exhibit stable interactions for methyl, bromide and hydrogen substituents, in particular. In comparison to quinoline-3-carboxamide derivatives, both the plant derivatives reveal highly unstable interactions.

However, the interaction with heterocomplex (4GGF), reveal most stable interaction for metabolite1 from Toddalia sp. Thermodynamic interaction of quinolinecarboxamide derivative 1, is also found to be very stable. Second Metabolite obtained from Toddalia, exhibited successful docking, but the interaction, although stable, is found to be weaker than that of quinolinecarboxamide derivatives as $-\mathrm{H},-\mathrm{CH} 3,-\mathrm{SCH} 3,-\mathrm{Br}$ and that of metabolite1 obtained from Toddalia species. Electrostatic contribution enhanced stability of complexes, formed with target 4GGF, although vdW interactions stabilized complexes formed by homocomplex of S100A9.

The drug like characteristics of compounds are verified, with the structural properties and composition. The metabolites from $T$. aculeata show comparable properties with quinoline-3-carboxamide derivatives varying at R5 position (Qsub), apart from moderate or low risk of mutagenicity, and higher drug scores. Table 3, Figure 3 The cLogP values are the least for plant metabolites, in comparison to all the quinoline substituents taken

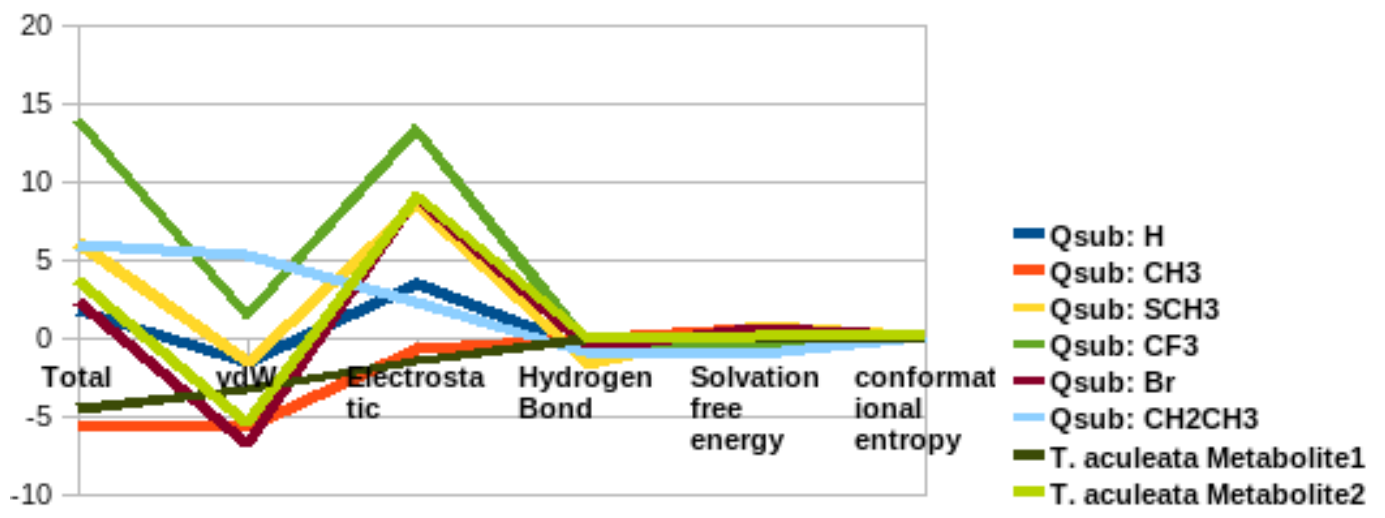

Figure 2(a): Energy analysis of complexes with S100A9(1IRJ).

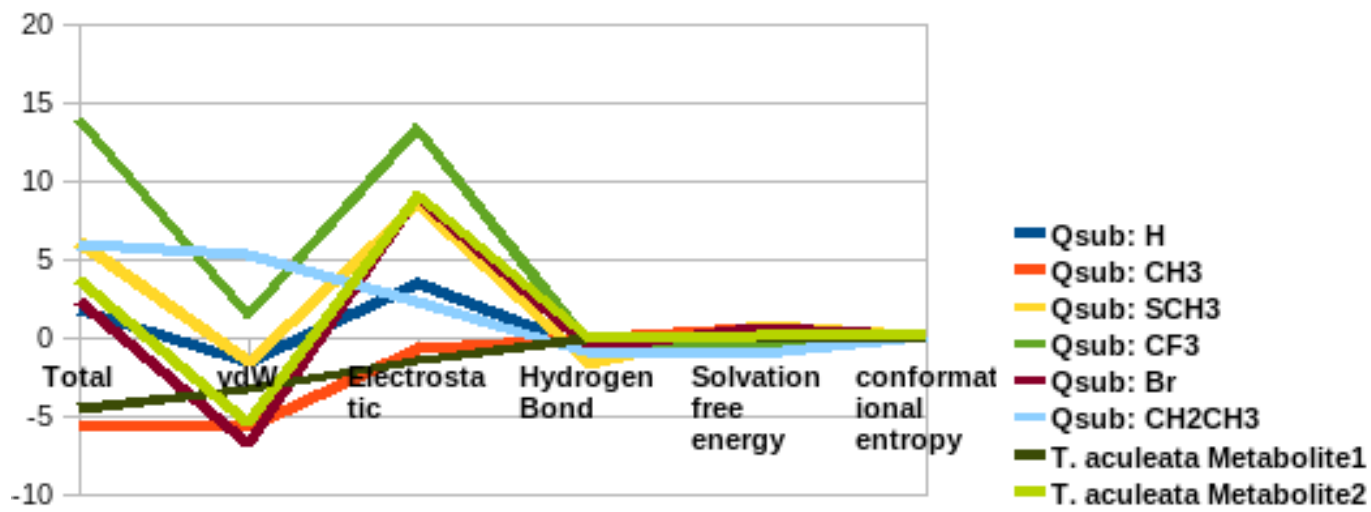

Figure 2(a): Energy analysis of complexes with S100A9(1IRJ). 


\begin{tabular}{|c|c|c|c|c|c|c|c|c|}
\hline \multicolumn{8}{|c|}{ Table 1: Molecular Properties of compounds docked with S100 member complexes } \\
\hline & $\begin{array}{c}\text { Qsub: } \\
\text { H }\end{array}$ & $\begin{array}{c}\text { Qsub: } \\
\text { CH3 }\end{array}$ & $\begin{array}{c}\text { Qsub: } \\
\text { SCH3 }\end{array}$ & $\begin{array}{c}\text { Qsub: } \\
\text { CF3 }\end{array}$ & $\begin{array}{c}\text { Qsub: } \\
\text { Br }\end{array}$ & $\begin{array}{c}\text { Qsub: } \\
\text { CH2CH3 }\end{array}$ & $\begin{array}{c}\text { T. aculeata } \\
\text { Metabolite1 }\end{array}$ & $\begin{array}{c}\text { T. aculeata } \\
\text { Metabolite2 }\end{array}$ \\
\hline LogP (<5) & 3.13 & 3.53 & 3.51 & 3.97 & 3.89 & 3.99 & 2.47 & 1.64 \\
\hline Topological PSA (A2) & 62.54 & 62.54 & 62.54 & 62.54 & 62.54 & 62.54 & 64 & 80.93 \\
\hline Mol. Wt. (Da) & 322.26 & 336.39 & 368.46 & 390.36 & 401.26 & 350.42 & 289.33 & 321.37 \\
\hline no. of Violation & 0 & 0 & 0 & 0 & 0 & 0 & 0 & 0 \\
\hline rotatable bonds & 3 & 3 & 4 & 4 & 3 & 4 & 3 & 5 \\
\hline Volume (m3/mol) & 293.5 & 310.06 & 328.1 & 324.8 & 311.39 & 326.87 & 263.91 & 299.33 \\
\hline
\end{tabular}

\begin{tabular}{|c|c|c|c|c|c|c|c|c|c|}
\hline $\begin{array}{c}\text { S100 } \\
\text { Complex }\end{array}$ & Energy(Kcal/mol) & $\begin{array}{c}\text { Qsub: } \\
\text { H }\end{array}$ & $\begin{array}{l}\text { Qsub: } \\
\text { CH3 }\end{array}$ & $\begin{array}{l}\text { Qsub: } \\
\text { SCH3 }\end{array}$ & $\begin{array}{l}\text { Qsub: } \\
\text { CF3 }\end{array}$ & $\begin{array}{l}\text { Qsub: } \\
\text { Br }\end{array}$ & $\begin{array}{l}\text { Qsub: } \\
\text { CH2CH3 }\end{array}$ & $\begin{array}{c}\text { T. aculeata } \\
\text { Metabolite1 }\end{array}$ & $\begin{array}{c}\text { T. aculeata } \\
\text { Metabolite2 }\end{array}$ \\
\hline & Total & 1.81 & -5.75 & 6.16 & 13.97 & 2.33 & 6 & -4.57 & 3.74 \\
\hline & vdW & -1.53 & -5.67 & -1.53 & 1.46 & -6.77 & 5.39 & -3.27 & -5.43 \\
\hline & Electrostatic & 3.48 & -0.67 & 8.55 & 13.36 & 8.94 & 2.33 & -1.43 & 9.09 \\
\hline & Hydrogen Bond & -0.63 & 0 & -1.63 & -0.47 & -0.69 & -0.94 & 0 & 0 \\
\hline & Solvation free energy & 0.3 & 0.58 & 0.75 & -0.33 & 0.66 & -0.97 & 0.13 & 0.1 \\
\hline $1 \mathrm{IRJ}$ & $\begin{array}{c}\text { conformational } \\
\text { entropy }\end{array}$ & 0.18 & 0.18 & 0.18 & 0.18 & 0.18 & 0.18 & 0 & 0.18 \\
\hline \multirow[b]{6}{*}{$1 \mathrm{XK} 4$} & Total & -2.52 & -5.81 & 7.99 & 2.61 & -1.42 & 14.48 & 9.62 & 5.77 \\
\hline & vdW & 1.25 & -3.13 & -6.05 & 1.75 & -2.02 & 7.71 & 5.75 & -3.41 \\
\hline & Electrostatic & -1.48 & -1.61 & 13.77 & 2.77 & 1.78 & 8.5 & 4.75 & 10.65 \\
\hline & Hydrogen Bond & -1.16 & -0.22 & 0 & 0 & -0.94 & -1.12 & 0 & -0.34 \\
\hline & Solvation free energy & -0.92 & -0.38 & 0.31 & -1.52 & 0.01 & -0.43 & -0.52 & -0.54 \\
\hline & $\begin{array}{c}\text { conformational } \\
\text { entropy }\end{array}$ & 0.18 & 0.18 & 0.18 & 0.18 & 0.18 & 0.18 & 0 & 0.18 \\
\hline \multirow[b]{6}{*}{ 4GGF } & Total & -13.93 & -12.7 & -15.55 & 2.89 & -11.63 & 3.83 & -17.75 & -4.35 \\
\hline & vdW & -5.58 & -5.15 & -4.23 & -0.86 & -4.42 & -4.47 & -6.81 & -1.65 \\
\hline & Electrostatic & -7.49 & -7.69 & -10.49 & 4.85 & -6.89 & 8.95 & -10.05 & -0.8 \\
\hline & Hydrogen Bond & -0.67 & 0 & 0 & -0.61 & 0 & -1.66 & -0.42 & -0.59 \\
\hline & Solvation free energy & -0.15 & 0.35 & -0.35 & -0.45 & 0.14 & 1.21 & 0.33 & -0.02 \\
\hline & $\begin{array}{l}\text { conformational } \\
\text { entropy }\end{array}$ & 0.18 & 0.18 & 0.18 & 0.18 & 0.18 & 0.18 & 0 & 0.18 \\
\hline
\end{tabular}

Table 3: Molecular properties indicating drug conform behaviour (\#Indicates the score for property)

\begin{tabular}{|c|c|c|c|c|c|c|c|c|}
\hline & $\begin{array}{c}\text { Qsub: } \\
\text { H }\end{array}$ & $\begin{array}{c}\text { Qsub: } \\
\text { CH3 }\end{array}$ & $\begin{array}{c}\text { Qsub: } \\
\text { SCH3 }\end{array}$ & $\begin{array}{c}\text { Qsub: } \\
\text { CF3 }\end{array}$ & $\begin{array}{c}\text { Qsub: } \\
\text { Br }\end{array}$ & $\begin{array}{c}\text { Qsub: } \\
\text { CH2CH3 }\end{array}$ & $\begin{array}{c}\text { T. aculeata } \\
\text { Metabolite1 }\end{array}$ & $\begin{array}{c}\text { T. aculeata } \\
\text { Metabolite2 }\end{array}$ \\
\hline cLogP & 2.3 & 2.62 & 2.8 & 3.07 & 3 & 2.98 & 1.36 & 1.09 \\
\hline logs & -3.3 & -3.64 & -4.14 & -4.07 & -4.13 & -3.8 & -2.67 & -2.31 \\
\hline Mol. Wt. \# & 0.89 & 0.88 & 0.83 & 0.79 & 0.77 & 0.96 & 0.93 & 0.9 \\
\hline Drug-likeness\# & 1 & 1 & 1 & 0.26 & 0.99 & 1 & 0.9 & 0.99 \\
\hline Risk-Mutagenicity\# & 0.6 & 0.6 & 0.6 & 0.6 & 0.6 & 0.6 & 0.8 & 1 \\
\hline Risk-Tumorigenicity\# & 0.6 & 0.6 & 0.6 & 0.6 & 0.6 & 0.6 & 1 & 1 \\
\hline Drug-score & 0.3 & 0.29 & 0.27 & 0.16 & 0.28 & 0.28 & 0.69 & 0.9 \\
\hline
\end{tabular}




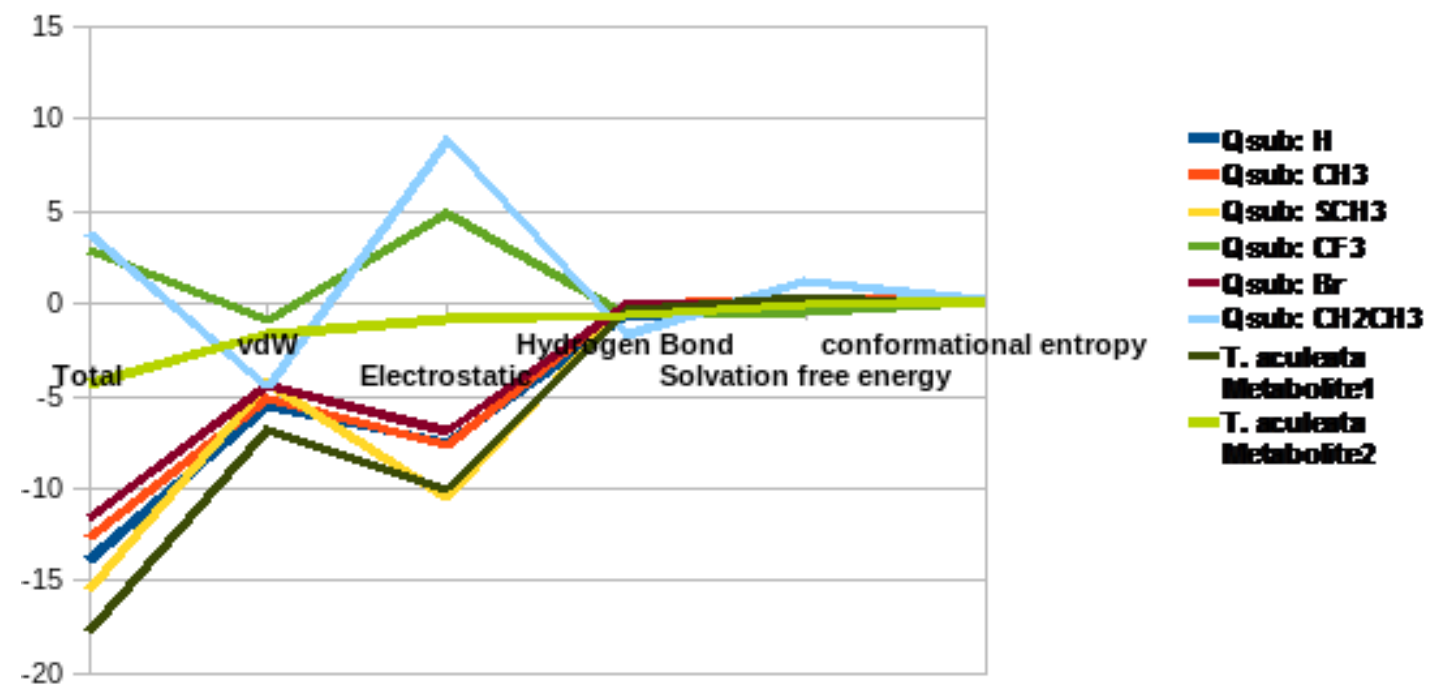

Figure 2(c): Energy analysis of heterocomplexes with S100A9(4GGF).

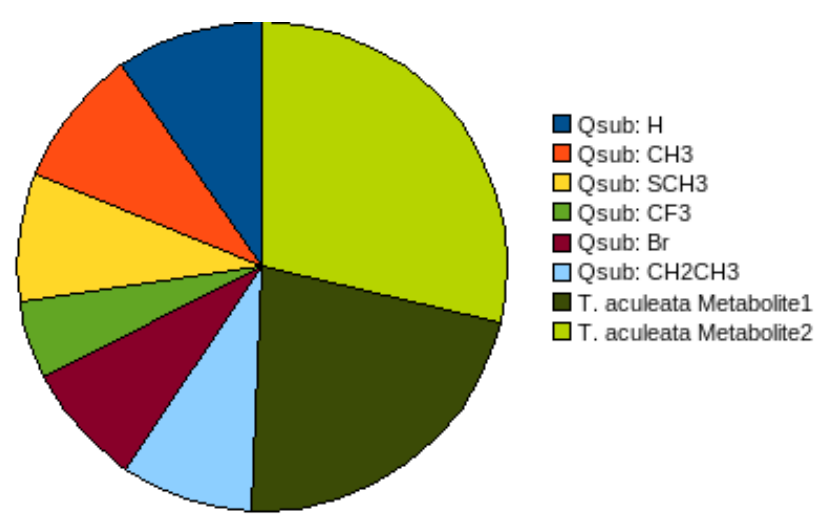

Figure 3: Ligand Drug-conform properties score.

for the study. Compound property scores based on the molecular weight, druglikeness, the risk involved in the complex based on mutagenicity or tumorigenicity is higher which indicates, they form better ligands due to their structural properties, to be used as a potential drug. The high drug scores obtained, for the two plant metabolites, indicate the possible use of metabolites as potential drug, to target S100 protein family members, including homo and heterocomplexes, based on the drug-conform properties of metabolites exhibited.

\section{CONCLUSION}

S100 protein families are found to be important mediators, in intracellular and extracellular function. They bind intracellularly and extracellularly to many receptors as, RAGE a receptor for advanced glycation end products, TNF- $\alpha$, and their binding is found to be specific. They essentially bind $\mathrm{Ca} 2+$ and $\mathrm{Zn} 2+$, for carrying out numerous biologically important functions, apart from binding to other ligands and numerous targets. Binding of the member polymeric forms of S100A9 and heteromer S100A8/S100A9, to quinoline-3-carboxamide derivatives, exhibit an inhibitory effect on their targeted biological interaction. $\mathrm{Ca} 2+$ and $\mathrm{Zn} 2+$ accelerates and increase, the binding of quinolinecarboxamide derivatives with the receptors. This eventually diminishes biological activity of S100 protein members, which otherwise lead to biological problems as, an unfavourable inflammatory response.

Quinoline derivatives from T. aculeata exhibit stable interactions, but are selective in forming stable complexes with S100 protein family complexes. The first metabolite obtained from T. aculeata form stable interactions, with the homocomplex of S100A9 protein (1IRJ), and the interactions are comparable to interactions, exhibited by methyl derivative of quinoline-3-carboxamide. Varying stability is exhibited, however, by both metabolites, in binding to one of the heterocomplexes of S100 (4GGF). Interactions of quinoline derivative, metabolite1 from the plant source, is better than the most stable interactions, exhibited by the quinolinecarboxamide derivative, with the $-\mathrm{CH} 3$ substituent. Binding of metabolite 2 from Toddalia species, although exhibit stability in its interaction with the heterocomplex, the total energy of interaction is found to be much higher than that exhibited by various substituents of quinoline carboxamides, as well as that obtained from the interaction of metabolite1, with the heterocomplex of S100 proteins.

The results indicate, metabolites from T. aculeata form, promising leads as indicated by their binding activity and properties. Further analysis of these compounds, based on their pharmacokinetics properties, would ascertain their use as an alternate effective medicine 
fordiseases involving specific targeting of S100 protein family members.

\section{ACKNOWLEDGEMENT}

- The resources and support provided for the study by Department of Science and Technology, INDIA at BiomolecularComputation Laboratory, DCDS (BIC), IISc, Bangalore is acknowledged.

- The generous support and facility for carrying out part of the study at Biomolecular Computational Laboratory, DCDS, IISc, Bangalore is acknowledged.

- The opportunity provided to undertake the research work by Dept. of Biochemistry, Periyar University, Salem is acknowledged.

\section{CONFLICT OF INTEREST}

Conflict of interest declared none.

\section{ABBREVIATION USED}

ADMET properties: Absorption-DistributionMetabolism-Excretion-Toxicity; Ca2+: Bivalent calcium ion; EF hand: Helix-loop-helix topology found in calcium-binding protein; Molecular Wt: Molecular Weight; MRP: Multidrug Resistance Proteins; NMR: Nuclear Magnetic Resonance; Qsub: Quinoline substituent; R5: Residue substitution position 5; RAGE:Receptor for Advanced Glycation End-products; SAR:Structure-activity relationship; S100A9: Afamily of cellular antigens proteins; TLR4/MD2: Toll-like receptor 4; TNF- $\alpha$ : Tumor necrosis factor; T. aculeate: Toddaliaaculeate; vdW: Van der Waal interaction; Zn2+: Bivalent Zinc ion.

\section{REFERENCES}

1. Wolfgang $\mathrm{N}$, et al. S100A9/S100A8: Myeloid representatives of the S100 protein family as prominent players in innate immunity. Microscopy Research and Technique. 2003;60(6):569-80.https://doi.org/10.1002/jemt.10299; PMid:12645005.

2. Thomas $\mathrm{V}$, et al. Mrp8 and Mrp14 are endogenous activators of Toll-like receptor 4, promoting lethal, endotoxin-induced shock. Nature Medicine. 2007;13(9):1042-9.https://doi.org/10.1038/nm1638 ; PMid:17767165.

3. John $\mathrm{BH}$, et al. S100A8 and S100A9 mediate endotoxin-induced cardiomyocyte dysfunction via the receptor for advanced glycation end products. Circulation Research. 2008;102(10):1239-46.https://doi. org/10.1161/CIRCRESAHA.107.167544; PMid:18403730.

4. Per B, et al. Identification of human S100A9 as a novel target for treatment of autoimmune disease via binding to quinoline-3-carboxamides. PLoSBiology. 2009;7(4):800.

5. Vogl, Thomas, Gharibyan AL, Ludmilla A. Morozova-Roche. Pro-inflammatory S100A8 and S100A9 proteins: self-assembly into multifunctional native and amyloid complexes. International Journal of Molecular Sciences. 2012;13(3):2893-2917.https://doi.org/10.3390/ijms13032893 ; PMid:22489132 PMCid:PMC3317694.
6. Kohtaro I, et al. The structure of human MRP8, a member of the $\mathrm{S} 100$ calcium-binding protein family, by MAD phasing at $1.9 \AA$ resolution. ActaCrystallographica Section D: Biological Crystallography. 2000;56(5):55966. https://doi.org/10.1107/S0907444900002833.

7. Hiroshi I, et al. The crystal structure of human MRP14 (S100A9), a $\mathrm{Ca}_{2}{ }^{+-}$ dependent regulator protein in inflammatory process. Journal of Molecular Biology. 2002;316(2):265-76.https://doi.org/10.1006/jmbi.2001.5340; PMid:11851337.

8. Thomas V, et al. Biophysical characterization of S100A8 and S100A9 in the absence and presence of bivalent cations. BiochimicaetBiophysicaActa (BBA)-Molecular Cell Research. 2006;30;1763(11):1298-306.

9. Rosario D. Intracellular and extracellular roles of $\mathrm{S} 100$ proteins. Microscopy Research and Technique. 2003;60(6):540-51.https://doi.org/10.1002/ jemt.10296 ; PMid:12645002.

10. Rosario $D$. Functional roles of $\mathrm{S} 100$ proteins, calcium-binding proteins of the EF-hand type. BiochimicaetBiophysicaActa (BBA)-Molecular Cell Research. 1999;8;1450(3):191-231

11. Narumi K, Miyakawa R, Ueda R, Hashimoto H, Yamamoto Y, Yoshida T, et al. Pro-inflammatory proteins S100A8/S100A9 activate NK cells via interaction with RAGE. The Journal of Immunology. 2015;1;194(11):5539-48.

12. Vogl T, Gharibyan AL, Morozova-Roche LA. Pro-inflammatory S100A8 and S100A9 proteins: self-assembly into multifunctional native and amyloid complexes. International journal of molecular sciences. 2012;5;13(3):2893-917.

13. Gilston BA, Skaar EP, Chazin WJ. Binding of transition metals to S100 proteins. Science China Life Sciences. 2016;59(8):792-801.https://doi. org/10.1007/s11427-016-5088-4 ; PMid:27430886 PMCid:PMC5123432.

14. Jesse G, Geczy CL. Inflammation-associated $\mathrm{S} 100$ proteins: new mechanisms that regulate function. Amino Acids 2011;1;41(4):821-42.

15. Kharb $\mathrm{R}$, Kaur $\mathrm{H}$. Therapeutic significance of quinoline derivatives as antimicrobial agents. International Research Journal of Pharmacy. 2013;4(3):63-9.https://doi.org/10.7897/2230-8407.04311.

16. Naeem A, Badshah SL, Muska M, Ahmad N, Khan K. The current case of quinolones: synthetic approaches and antibacterial activity. Molecules. 2016;28;21(4):268.

17. Jain S, Chandra V, Jain PK, Pathak K, Pathak D, Vaidya A. Comprehensive review on current developments of quinoline-based anticancer agents. Arabian Journal of Chemistry. 2016;26. https://doi.org/10.1016/j. arabjc.2016.10.009.

18. Alexander GP, de Dios A, Roepe PD. Quinoline drug-heme interactions and implications for antimalarial cytostatic versus cytocidal activities. Journal of Medicinal Chemistry. 2013;56(13):5231-46.https://doi.org/10.1021/ jm400282d ; PMid:23586757.

19. Sandeep $\mathrm{S}$, et al. Quinoline and quinolones: promising scaffolds for future antimycobacterial agents. Journal of Enzyme Inhibition and Medicinal Chemistry. 2014;1-13.

20. Qizhu D, Jia G, Lown JW. Synthesis and antitumor cytotoxicity evaluation of pyrido [4, 3, 2-de] quinolines and isoquinolino [6, 5, 4, 3-cde] quinolines. AntiCancer Drug Design. 2000;1;15(2):99-108.

21. Kaur G, Yadav R. Anti-cancer activities of various heterocyclic containing entities- a review. International Journal of Natural Product Science. 2012;1:104.

22. Per B, et al. Identification of human $\mathrm{S} 100 \mathrm{~A} 9$ as a novel target for treatment of autoimmune disease via binding to quinoline-3-carboxamides. PLoSBiology. 2009;7(4):800.

23. Johannes S. World spice plants: economic usage, botany, taxonomy. European Union: Springer. 2005.

24. Keerthana GM. Optimization of callus induction, phytochemical characterization and anti-inflammatory effect of Toddalia aculeata from Kolli Hills- Tamil Nadu; Doctoral Dissertation, Department of Biochemistry, Periyar University, Salem- 636 011, Tamil Nadu, India; 2014.

25. Prashant DV, et al. Identification of novel parasitic cysteine protease inhibitors by use of virtual screening. 2 . The available chemical directory. Journal of Medicinal Chemistry. 2006;9;49(5):1576-84.

26. Harry PE, Williams A. Chem Spider: an online chemical information resource. 2010:1123-4.

27. Aalten DM, Bywater R, Findlay JB, HendlichM, Hooft RW, Vriend G. PRODRG, A Program for generating molecular Topologies and Unique molecular descriptors from coordinates of small molecules. Journal of Computer-Aided 
Molecular Design. 1996;10(3):255-62.https://doi.org/10.1007/BF00355047 ; PMid:8808741.

28. Koch MA, Schuffenhauer A, Scheck M, Wetzel S, Casaulta M, Odermatt A, et al. Charting biologically relevant chemical space: a structural classification of natural products (SCONP). Proceedings of the National Academy of Sciences of the United States of America. 2005; 29;102(48):17272-7. https:// doi.org/10.1073/pnas.0503647102.

29. Rose PW, Bi C, Bluhm WF, Christie CH, Dimitropoulos D, Dutta S, et al. The RCSB Protein Data Bank: new resources for research and education. Nucleic Acids Research. 2013;1;41(D1):D475-82.
30. Sander T. OSIRIS property explorer. Allschwil: Actelion Pharmaceuticals Ltd. 2001.

31. Wendy WA. App-etite for change. Journal of Computer-aided Molecular Design. 2015;29(4):297.https://doi.org/10.1007/s10822-014-9824-1; PMid:25515639.

32. Macindoe G, Mavridis L, Venkatraman V, Devignes MD, Ritchie DW. Hex Server: an FFT-based protein docking server powered by graphics processors. Nucleic Acids Research. 2010;5:gkq311.

33. Han LY, et al. PEARLS: Program for energetic analysis of receptor- ligand system. Journal of Chemical Information and Modeling. 2006;46(1):445-50. https://doi.org/10.1021/ci0502146 ; PMid:16426079.

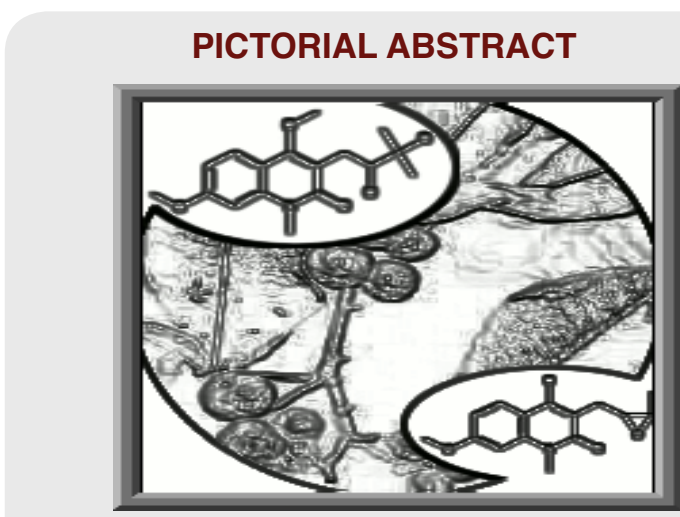

Author Profile

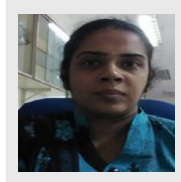

Vidhya Meleveetil: Research Scholar, Department of Biochemistry, Periyar University, Salem (Tamil Nadu), India.

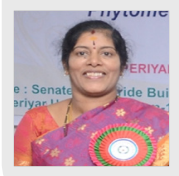

Dr. Suriyavathana Muthukrishnan: Asst. Professor, Department of Biochemistry, PeriyarPalkalai Nagar, Salem, Tamil Nadu - 636011, India.

\section{SUMMARY}

- Quinoline derivatives, in general; are identified to possess pharmacological characteristics, as anti-cancer, anti-inflammatory, anti-malarial etc. Quinoline derivatives, containing quinolone scaffold are obtained from different sources, also as a part of phytoconstituents. These compounds play an important role in secondary metabolism including defense in plants. The structural characteristics of the derivatives of quinolone from the plant source available in Kolli hills of Tamil Nadu, identified as Toddalia aculeate are differentiated for their structural characteristics, and their interaction with the calcium binding $\$ 100$ target proteins, S100A8 and S100A9 studied. Results indicate, the interaction with homo and heterocomplexes of $\mathrm{S} 100$ proteins are found to be varying and differentiated based on their docking and dynamic interactions.

- The study identifies the lead like and possible drug like properties of phytoderivatives, the quinolone derivatives obtained from Toddaliaaculeate. Theirinteractions are comparable with the interaction of original ligands, duringcomplex formation with S100 member targets.

Cite this article: Suriyavathana M, Vidhya M. Calprotectin Complex Interactions with Phytoquinolines and New Target Binding Alternates Calprotectin complex and Phytoquinolines. Indian $\mathrm{J}$ of Pharmaceutical Education and Research. 2017;51(4):656-63.
} 